\title{
A Safari in Brazil: evidence regarding the Framework-Based Approach to Teaching*
}

\author{
Patrícia de Souza Costa \\ Universidade Federal de Uberlândia, Faculdade de Ciências Contábeis, Uberlândia, MG, Brazil \\ Email: patricia.costa@ufu.br
}

\section{Gilvania de Sousa Gomes}

Universidade Federal de Uberlândia, Faculdade de Ciências Contábeis, Uberlândia, MG, Brazil Email: gigilvania@yahoo.com.br

\section{Guillermo O. Braunbeck}

Universidade de São Paulo, Faculdade de Economia, Administração e Contabilidade, Departamento de Contabilidade e Atuária, São Paulo, SP, Brazil Email: braunbeck@usp.br

\section{Maria Eduarda Gomes Santana}

Universidade Federal de Uberlândia, Faculdade de Ciências Contábeis, Uberlândia, MG, Brazil Email: mariaeduardacontabeis@hotmail.com

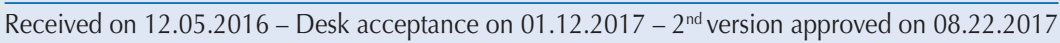

\begin{abstract}
This study aims to present the results of using the Open Safari case for teaching in the Accounting Sciences course of a Brazilian public university, and obtain evidence regarding its effectiveness in developing the skills and competencies needed for learning and applying International Financial Reporting Standards (IFRS), by analyzing the results in light of the Bloom Taxonomy. The use of cases for teaching has been shown to be an efficient mechanism for developing and improving skills and competencies, and IFRS Education considers the method conducive to teaching based on the Conceptual Framework of the International Accounting Standards Board (IASB). The research was carried out with the participation of 159 students enrolled in the Accounting Theory (AT) discipline in 2013 and 2014. In addition, five focus groups were formed, with an average of eight students each. The results of the research suggest that in the students' perception the Open Safari case helps in developing skills and competencies, especially those related to exercising judgment and accounting choices associated with IFRS and the critical ability to consider different possibilities, which is a typical scenario in the corporate environment. The skills indicated as being the most improved are linked to the ability to consider more than one solution for real problems, to interpreting scenarios, to consolidating various contents of the discipline and the course, to associating these with practice, and developing critical thinking and an individual responsibility for one's own learning. The case was even shown to be efficient in accessing more sophisticated levels of the Cognitive Domain of acquisition and consolidation of knowledge of the Bloom Taxonomy. This study contributes by reinforcing the idea that the Open Safari case fulfills the aims of IFRS Education for the Framework-Based Approach to Teaching.
\end{abstract}

Keywords: conceptual framework, IFRS Education, Open Safari case, teaching accounting, Framework-Based Approach to Teaching.

Correspondence address:

Patrícia de Souza Costa

Universidade Federal de Uberlândia, Faculdade de Ciências Contábeis

Avenida João Naves de Ávila, 2121, Bloco 1F, Sala 1F-215 - CEP: 38400-902

Campus Santa Mônica - Uberlândia - MG - Brazil

*Paper presented at the Annual Meeting of the American Accounting Association, New York, NY, United States of America, August 2016, and at the XVII USP International Conference on Accounting, São Paulo, SP, July 2016. 


\section{INTRODUCTION}

This study aims to verify the effectiveness of the Open Safari case in developing skills and competencies needed for understanding and applying International Financial Reporting Standards (IFRS), in light of the Bloom Taxonomy. The material Stage 3 - Non-financial assets: the Open Safari case study (Wells \& Tarca, 2014a) is an integral part of those developed by the educational initiative of the International Accounting Standards Board (IASB) within the scope of the IFRS teaching approach known as the Framework-Based Approach to Teaching (FBAT).

The use of cases for teaching and learning based on problems, known as Problem-Based Learning (PBL), has increased in accounting teaching due to its usefulness in developing or improving skills and competencies (Weil, Oyelere, Yeoh, \& Firer, 2001) and Open Safari forms part of the movement that recognizes the importance of using the method to achieve this aim. Such techniques have commonly been used in management accounting; however financial accounting also represents fertile terrain for applying this type of strategy, especially after IFRS convergence. These standards require abilities from accounting professionals to carry out estimates and judgments with a high degree of subjectivity.

The PBL method is aligned with the principles of experimental learning since it enables students, by means of concrete situations, to reproduce decisionmaking environments (Dewey, 1981). Taking questions linked to philosophy and psychology into account, this author acted in constructing the Experimental Theory of Knowledge. According to this theory, the knowing, wanting, feeling, and other states of consciousness are defined in terms of acts and attitudes contained in the experience, which should be considered synonymous with education. According to this author, experiences are genuinely educational and can be acquired using active methodologies, such as cases for teaching (Nath, 2005).

The Accounting Education Change Commission (AECC, 1990) suggests that using cases for teaching can help in the development of abilities that are desirable for accounting professionals, such as intellectual, interpersonal, attitudinal and communication skills, as well as general knowledge and business and accounting knowledge. Based on this proposition, Weil et al. (2001) tried to verify whether students in South Africa who used cases for teaching thought that the method was more effective in developing skills and comeptencies than students subjected to conventional teaching techniques, such as reading, seminars, tutorials, and tradiational classes. This investigation was motivated by the preliminary study by Weil, Laswad, Frampton, and Radford (1999), which analyzed the perception of students in Malaysia with regards to the use of cases for teaching management accounting. These authors found that the main benefit perceived by the students when cases were used for teaching was the integration and application of the knowledge in solving real-world problems; that is, interating theory and practice.

According to the International Accounting Standards Board (IASB, 2015), 116 jurisdictions, including Brazil, require the financial statements of all (or most) entities that must publish accounts publicly to be elaborated in compliance with IFRS. Thus, considering that IFRS adoption is a reality for an expressive number of countries in the world, its teaching has come to be the object of increasing interest, particularly due to the challenge that this accounting standard presents in terms of professional training to carry out the judgments needed for its application (Hodgdon, Hughes, \& Street, 2011). In this context, the FBAT is evaluated by various authors (Bonnier, Demerens, Hossfeld, \& Le Mahn, 2013; Coetzee \& Schmulian, 2013; Hilton \& Johnstone, 2013; Jackling, De Lange, \& Natoli, 2013) as being effective in the development of these skills.

In light of above, teaching IFRS requires the development of specific skills and competencies, cases for teaching have been used as an efficient mechanism for this purpose, and the Open Safari case was also created with this aim. Also, no evidence of empirical results was found in the literature for the application of the Open Safari case in accounting courses. Brought to the context, these factors reveal the research gap and opportunity. Thus, the question that the results aim to answer is linked to the effectiveness of the Open Safari case in developing the skills and competencies needed to understand and apply IFRS.

The aim of this research is to analyze whether the Open Safari case is appropriate for improving skills and competencies required for learning and applying IFRS, using the experience of applying the case in a Brazilian federal public university, and based on the reference framework for using cases as an appropriate tool and the educational objectives laid out by the Bloom Taxonomy.

The results of this research can serve the IASB as a source of feedback regarding the effects of using the case and signal the achievement of its initial objectives or indicate new demands and difficulties in relation to its 
understanding and interpretation, since reports on its application are not yet frequent, as well as results related to its use in teaching IFRS and in improving the skills and competencies that the case proposes.

Also, this study can be useful for teachers and students all over the world in presenting the results of the experience of applying the Open Safari case in the Accounting Sciences course of a Brazilian public university, especially in the Accounting Theory (AT) discipline. In this area, the students benefit by improving their experience of learning IFRS and acquiring new abilities, which results in advantages for the market in the form of better trained professionals. In turn, teachers can gain from the possibility of having viable alternatives on hand for use in teaching accounting content related to IFRS, which is an element that is also reflected in benefits to the teaching institution in terms of the quality of their training.

In addition, the research confirms that the use of cases for teaching, specifically the Open Safari case, is useful for developing skills and competencies, and is thus consistent with studies such as those by Weil et al. (2001). Moreover, it was possible to establish correlations between the aims of the IASB's educational initiative and the consolidation of the learning process described in the Bloom Taxonomy, confirming not only the usefulness of the case as an important didactic resource, but also in relation to the effective learning of the contents of the AT discipline and to the integration with contents addressed in other disciplines of the course, showing the interdisciplinary reach of the Open Safari case for teaching accounting. Furthermore, it is verified that it fulfilled its proposed role of being valid for teaching nonfinancial assets, with reasoning developed based on the Conceptual Framework.

Two contributions from the research lie here: (i) theoretical, by adding to the literature the result of applying the Open Safari case to the list of studies on this teaching-learning mechanism, especially within the sphere of financial accounting, and by associating, via the presentation of results, the didactic aim of the cases for teaching, calculated here using the instruments proposed by Weil for the Bloom Taxonomy, intertwined in the Open Safari case since its conception; and (ii) practical, in demonstrating how much using the case is useful for teaching accounting contents in an interdisciplinary way.

\section{THEORETICAL PLATFORM}

\subsection{Educational Initiative and the Framework- Based Approach to Teaching}

In the first years of the IASB's existence, it was already possible to observe concerns that went beyond issuing high quality international accounting standards. The coherent application of these standards in the different jurisdictions and countries that adopt them or allow their application in the elaboration of the financial statements of their entities is already observable in the strategic actions of the International Accounting Standards Committee (IASC), the entity that supports IASB. Thus, in 2005 (IASC Foundation, 2006) teaching materials started to be developed that could offer support to teachers in teaching IFRS. And one of the ways is to prepare free teaching materials designed to enable the students to develop the skills to carry out the judgments and estimates needed to apply IFRS (IASB, 2014). Here lies a fundamental point in the Framework-Based Approach to Teaching: the Conceptual Framework of the IFRS (a fundamental pillar of the FBAT), designed to provide the concepts needed for the development of the IFRS standards and their application (IASB, 2014), states laconically that: "to a great extent, financial reports are based on estimates, judgments, and models, and not on exact representations" (IASB, 2013, A22).

The enormous educational challenges that underlies the adoption of standards that are predictive in character (i.e., focused on informational utility) and based on principles has already been observed by Schipper (2003) when analyzing the impacts of their adoption in the particular case of the Generally Accepted Accounting Principles in the United States - US GAAP, which share a similar conceptual framework to that used by the IASB in the elaboration of IFRS. While the existence of a robust conceptual framework is not a sufficient condition for a set of principles-based standards, it is understood that it is a necessary condition, for which reason we aim to evaluate the effectiveness of the FBAT as a way of facing the educational challenge observed by Schipper (2003). The view that a robust conceptual framework is the foundation for a set of principles-based standards was developed by Kabureck (2016).

Thus, there appears to be a reasonable consensus that preparing future accountants for standards such as IFRS or US GAAP requires the development of skills that enable them to exercise often complex professional judgments 
and carry out estimations that enable financial reports to "translate" the future cash flow expectations presented in them.

By rooting teaching in the concepts concerning the accounting standards, Wells (2011) indicates that the FBAT sets the foundations for a more robust and cohesive understanding of the accounting requirements by IFRS students. By understanding the "whys" before the "whats" and "hows", the specific accounting requirements contained in each IFRS will be better understood in a full set of IFRS and based on the objective of financial reports, which offers a more robust basis for carrying out the judgments and estimates needed to apply IFRS. This view is consistent with that of Jackling (2013), who concludes that teaching financial accounting should start with an understanding of the Conceptual Framework, given that it establishes the concepts underlying the preparation and presentation of financial statements for external users. In other words, as the IFRS standards are principles-based and therefore require the use of professional judgment and estimations in expressive doses, an understanding of the aims and concepts before the specific principles and rules for specific events and transactions enables the development of the skills needed to apply the specific requirements contained in the IFRS (Hodgdon et al., 2011).

Wells (2011) suggests that the Framework-Based Approach to Teaching basically covers three sequential stages at any moment in teaching financial accounting, namely: $1^{\text {st }}$ stage: addressing the economic fundamentals of the transaction or event, especially as the object of the class or course; $2^{\text {nd }}$ stage: discussing what would be the information regarding the transaction or event in particular that is being studied that offers investors and creditors useful content concerning the resources (or demands) resulting from this transaction and that therefore give them the opportunity to evaluate its effects on future cash flows for the entity; $3^{\text {rd }}$ stage: addressing the specific requirements of IFRS with regards to identifying, recognizing, measuring, presenting, and reporting the transaction or event that is being studied.

It bears mentioning that in the $3^{\text {rd }}$ stage situations can arise in which the specific accounting requirement of an IFRS may not be coherent with the concepts established in the Conceptual Framework. In connection with this, Wells (2011) warns that applying the Framework-Based Approach to Teaching is not complete in situations in which the requirements for a specific transaction or event are incoherent with the concepts of the Conceptual
Framework. However, it is observed that in the materials produced by the educational initiative, these situations of inconsistency between the concepts of the Conceptual Framework and requirements of particular standards are addressed and employed as part of the learning of the standards that address a transaction or event individually.

As examples of learning via situations in which there is incoherence between a specific requirement and the Conceptual Framework (Wells \& Tarca, 2014b), it is possible to identify the case studies developed by Braunbeck and Wells (2015) and Wells and Tarca (2013). In the first case (Wells \& Tarca, 2014a), the authors present a situation in which the company loses the control of an asset, but that asset continues to generate future benefits. It is observed that under IAS 16 Fixed Assets the asset that is no longer controlled should not be written off. This is because on one hand IAS 16 requires an item that has been disposed of, or one in which there are no longer expectations of future benefits, to be written off (i.e., there is no mention with regards to control). In the case of the asset analyzed, there was no disposal nor were the expectations of future economic benefits lost. On the other hand, according to the Conceptual Framework, an asset must be a resource over which the entity maintains control, which would not be present in the case discussed. There is therefore an inconsistency between the criteria for the existence of an asset in the Conceptual Framework (control) and the requirements for writing off a fixed asset in IAS 16 (which does not mention control).

In the second case (Braunbeck \& Wells, 2015) a financial instrument is observed in which an implicit derivative contains potential future economic benefit. However the specific standards that addresses the recognition of financial instruments does not consent with the separation of that implicit derivative. The reason for the exception is discussed in the support material for teachers and configures a teaching and learning element.

This perception that even the incoherencies and deviations from the specific IFRS in relation to the Conceptual Framework should be "raw material" for the learning is shared by the ex-president of the IASB himself, Sir David Tweedie (Street, 2002), who expressed that universities should be a space where the problems of the standards are explored and where there is a search to understand their reasons and also understand that they are the best answer from the accounting standards issuing body at a particular point in time and in a particular context. Tweedie states that accounting students should thus be taught to think (Street, 2002). 


\subsection{The Open Safari Case and the Bloom Taxonomy}

Given the need to learn critical thinking in order to employ the international standards, in practical terms of applying the FBAT to fixed assets and other non-financial assets, its creators claim that this can be implemented at all levels in which IFRS are taught (Wells \& Tarca, $2014 b$ ). As the number of IFRS requirements addressed and the level of integration with other IFRS topics and related disciplines (for example, finance, tax accounting, economics, and statistics) vary, depending on the course objectives and the level at which the standards are taught, the FBAT establishes teaching objectives regarding IFRS estimates and other judgments that begin with "awareness", move on to "understanding", and reach the highest level of "competency".

Based on this idea of progressive growth, which begins with awareness and reaches its highest level at competency, the Framework-Based Approach to Teaching divides an accountant's path of teaching into three stages, namely: stage 1 (Awareness) - applicable to the first course(s) in financial accounting; stage 2 (Understanding) - applicable to course(s) in financial accounting lying in the middle of the path towards professional certification as an accountant; and stage 3 (Competency) - applicable in the course(s) immediately prior to professional certification as an accountant.

While it is not explicitly referred to by its authors, the FBAT is compatible with the idea of the learning objectives, as systemized by Rothwell and Kazanas (1992) when they describe the objectives of the learning domains (particularly the Cognitive Domain), based on the Bloom Taxonomy for different levels. Table 1 systemizes the possible correlation to be established with the learning objectives in the Cognitive Domain, in their different levels and stages of the FBAT.

Table 1 Correlation between the Stages of the FBAT and the levels of the learning objectives in the cognitive domain of the Bloom Taxonomy

\begin{tabular}{|c|c|c|c|c|c|c|}
\hline \multirow{2}{*}{ Level } & \multirow{2}{*}{ Behavioral description } & \multirow{2}{*}{ Examples of instructional activities } & \multirow{2}{*}{ Verbs associated with the learning objective } & \multicolumn{3}{|c|}{ FBAT Stages } \\
\hline & & & & 1 & 2 & 3 \\
\hline 1 & $\begin{array}{l}\text { Remember and recognize } \\
\text { information }\end{array}$ & $\begin{array}{l}\text { Describe facts and statistics, } \\
\text { remember a process }\end{array}$ & $\begin{array}{l}\text { Organize, define, describe, label, list, memorize, } \\
\text { recognize, relate, reproduce, select, affirm. }\end{array}$ & $\bullet$ & $\bullet$ & $\bullet$ \\
\hline 2 & $\begin{array}{l}\text { Understand meaning, } \\
\text { repeat information in one's } \\
\text { own words, interpret, } \\
\text { extrapolate, translate }\end{array}$ & $\begin{array}{l}\text { Explain or interpret the meaning } \\
\text { of the scenario or statement, } \\
\text { suggest treatment, reaction, or } \\
\text { solution for a given problem, } \\
\text { create examples and metaphors }\end{array}$ & $\begin{array}{l}\text { Explain, reiterate, rephrase, criticize, classify, } \\
\text { summarize, illustrate, translate, review, } \\
\text { report, discuss, rewrite, estimate, interpret, } \\
\text { theorize, paraphrase, refer, exemplify. }\end{array}$ & $\bullet$ & & $\bullet$ \\
\hline 3 & $\begin{array}{l}\text { Use or apply knowledge, } \\
\text { theory in practice, use } \\
\text { knowledge, in response } \\
\text { to real situations }\end{array}$ & $\begin{array}{l}\text { Put theory into practice, } \\
\text { demonstrate, solve problems }\end{array}$ & $\begin{array}{l}\text { Use, apply, discover, manage, execute, resolve, } \\
\text { produce, implement, construct, change, prepare, } \\
\text { carry out, perform, react, respond, assume roles. }\end{array}$ & $\bullet$ & $\bullet$ & $\bullet$ \\
\hline 4 & $\begin{array}{l}\text { Interpret elements, } \\
\text { organizational principles, } \\
\text { structure, construction, } \\
\text { internal relationships }\end{array}$ & $\begin{array}{l}\text { Identify component parts } \\
\text { and functions of a process } \\
\text { or concept, carrying out a } \\
\text { qualitative evaluation of elements, } \\
\text { relationships, values, and effects }\end{array}$ & $\begin{array}{l}\text { Analyze, detail, catalogue, compare, } \\
\text { quantify, measure, test, examine, experiment, } \\
\text { relate, produce graphics and diagrams, } \\
\text { design, extrapolate, value, divide. }\end{array}$ & & & \\
\hline 5 & $\begin{array}{l}\text { Develop new singular } \\
\text { structures, systems, models, } \\
\text { approaches, creative thinking }\end{array}$ & $\begin{array}{l}\text { Develop plans and } \\
\text { procedures; integrate methods, } \\
\text { resources, ideas, parts }\end{array}$ & $\begin{array}{l}\text { Develop, plan, construct, create, design, } \\
\text { organize, revisit, formulate, propose, establish, } \\
\text { put together, integrate, reorder, modify. }\end{array}$ & & & $\bullet$ \\
\hline 6 & $\begin{array}{l}\text { Evaluate effectiveness of } \\
\text { integral concepts in relation } \\
\text { to values, products, viability; } \\
\text { critical thinking, comparison, } \\
\text { and strategic review; judgment } \\
\text { in relation to external criteria }\end{array}$ & $\begin{array}{l}\text { Review options in terms of } \\
\text { effectiveness and applicability; } \\
\text { analyze sustainability; carry } \\
\text { out analyses in relation } \\
\text { to alternatives; produce } \\
\text { explanations for a proposition }\end{array}$ & $\begin{array}{l}\text { Review, justify, analyze, present a case } \\
\text { for, defend, create a report on, investigate, } \\
\text { direct, evaluate, argue, manage a project. }\end{array}$ & & & • \\
\hline
\end{tabular}

Note: Level categories: 1 = Knowledge; 2 = Understanding; $3=$ Application; $4=$ Analysis; $5=$ Synthesis; $6=$ Evaluation .

Source: Elaborated by the authors based on Rothwell and Kazanas (1992). 
According to the approach suggested by Wells and Tarca (2014b), stage 1 corresponds to the first course in financial reports that a student should have. In this stage, they suggest that the learning process uses passages from the Conceptual Framework (objective, qualitative characteristics, definitions of the elements, and recognition criteria) and from the most important principles of the standard that should be applied to the phenomenon under analysis, merely aiming to raise awareness for judgments and estimates at this level.

As the first contact with the Conceptual Framework (excerpts) and the main principles of a standard, the application of this approach in stage 1 will require: "recognizing" transactions and events [e.g., in example 1, in Wells and Tarca (2014c), a piece of equipment is described and the student must recognize that this involves an asset based on the definition of the Conceptual Framework]; "relating/classifying" these transactions (e.g., also in example 1, the student should relate the characteristics of the acquired asset with the fixed asset, which will ultimately determine its accounting classification); and "applying/ preparing/implementing" [Wells and Tarca (2014c) suggest a tutorial via which it is proposed to the students that they apply the concepts and requirements of IFRS to a maritime transport company in order to record the fixed asset, its depreciation, and impairment losses, as well as preparing the corresponding accounting entries]. These learning activities reveal the relationship with levels 1 to 3 in Table 1 , in correlation with the stages of the FBAT and the levels of the learning objectives.

Stage 2, according to Wells and Tarca (2014b), is fundamentally different to stage 1 due to the deeper development of the abilities to carry out the judgments and estimates needed to apply IFRS. This is evident, for example, when the authors suggest the Basis for Conclusions as reference material, a document in which the IASB lays out the accounting treatment alternatives analyzed in the study phase and preparation of the standard, and the motives for the choices made, among other information that helps the student in more broadly and systemically understanding the standard (know why).

The authors also suggest the use of the financial statements of real companies as well as decisions and interpretations of the accounting standards by regulators. This increase in the width of the overview of the specific normative requirements goes on to demand from the students the development of their ability to "analyze" and "relate" elements studied up to here in isolation, in the hope of "understanding the structure of the standard and the relationship between the parts and the whole", which connects with level 4 of Table 1 with regards to the correlation with the stages of the FBAT and the learning objective levels.

At stage 3, the application of case studies is suggested (Wells \& Tarca, 2014b) as a tool to develop the competency required for carrying out the judgments and estimates needed to apply IFRS. This stage, according to the authors, differs from the former in the "integration", whether this is integration with other IFRS standards or topics, or with other disciplines. In the case studies, the maximum level of exercising judgment is required as well as carrying out estimates to address, for example, situations in which there are no standards that prescribe the accounting treatment to be used and for which the student should "develop/construct" a new accounting policy (e.g., in the case of Open Safari, there is a situation of a future sales contract for wood for which there is no standard that can be directly applied, and so analogies need to be sought and a compatible accounting policy constructed using the concepts of the Conceptual Framework).

Also, stage 3 characterizes the "investigation and critical evaluation" of situations in which the standards offer answers that are incompatible with the Conceptual Framework (e.g., in the Open Safari case, the student is presented with a concrete situation of government subsidies to eliminate lantana camara where the limited response offered by IAS 20 is discussed, showing clear signs of "ageing" of this standard, and comparatively, the informational virtues of the accounting answers produced for this same phenomenon by the IFRS for Small and Medium-Sized Companies, which is more recent and compatible with the Conceptual Framework). In this context, it is understood that stage 3 presents a correlation with levels 5 and 6 of Table 1, which associates the stages of the Framework-Based Approach to Teaching and the learning objective levels.

The use of case studies without standardized solutions in IFRS teaching is indicated by Bonnier et al. (2013) as a way of developing the students' ability to carry out judgments. These authors, also based on the Bloom Taxonomy, indicate that IFRS teaching should allow for a migration from a traditional model of repetition of accounting rules and requirements (repeat mode) to an analytical training model that enables the evaluation of scenarios and carrying out syntheses (find mode), which denotes the adequacy of instruments such as case studies in the pursuit of this aim.

Conceptually, the cases for teaching enable the students, via concrete situations, to reproduce decisionmaking environments, as prescribed by Experiential Learning Theory (Dewey, 1981). According to this theory, the knowing, wanting, feeling, and other states 
of consciousness are defined in terms of acts and attitudes contained in the experience, which should be considered synonymous with education. According to Dewey (1981), experiences are genuinely educational.

When referring to Dewey's Theory, LeBlanc, Léger, Lang, and Lirette-Pitre (2015) mention that the learning consists of the ability to evaluate a given experience and also that by means of inquiry this process becomes reflective and assigns meaning to the experiences via awareness, which can occur individually or collectively. These authors analyzed the use of cases for teaching as a pedagogical approach based on this theory. The intention was to test the active methodology and its contribution to the learning process, from the perspective of the students, teachers, and teaching institution. The conclusions of this study proved the effectiveness of using cases and can be considered a motivational element for students, teachers, and teaching institutions to rethink the educational processes.

Experiential learning was also tested in the area of management in the second year of an undergraduate course (Marin, 2015). The emphasis of the study was to analyze skills and competencies developed by the students in different dimensions. The students participated in simulations and inverted classes and then answered a questionnaire. The main conclusions were that the students acquired genuine knowledge via the experiences derived from the simulations.

In addition, one of the reasons for which cases became prominent as a teaching tool is that their use agrees with constructivist philosophy of education (Nath, 2005). Many educators think that cases provide a much more constructivist way of teaching, in which the instructors do not simply transfer knowledge to students, but rather help them to construct their own knowledge (Nath, 2005).

In the particular case of teaching fixed assets and other non-financial assets, the Open Safari case study was developed by Wells and Tarca (2014a) to support the teaching of judgments and estimates needed to apply IFRS related to this group of assets, and it should be used in stage 3 of the Framework-Based Approach to Teaching. This case involves the economic transactions and events of a fictitious company called Open Safari, which specializes in tourism in Africa, covering 10 financial years. After explaining the context of each period or grouped periods, questions are presented for discussion. In order to answer the questions, the students need to carry out surveys, simulate scenarios, and think conceptually. Besides integrating different areas of judgments and estimates in the context of various non-financial assets that form part of a corporate activity (the Open Safari conglomerate), a substantial portion of the situations presented in the case study is atypical. This requires the students to identify the underlying concepts of the IFRS in the search for and development of "accounting answers" that enable an understanding of the informational objectives of the IFRS reports and of the requirements of the specific IFRS standards.

\section{THE DATA COLLECTION INSTRUMENT AND THE BLOOM TAXONOMY}

The Bloom Taxonomy addresses three domains through which the learning process is consolidated: cognitive, affective, and pscychomotor. The cognitive level refers to the domain of some knowledge or the acquisition of new knowledge and covers the categories of complexity Knowledge, Understanding, Application, Analysis, Synthesis, and Evaluation (Ferraz \& Belhot, 2010). The Affective Domain covers postures and feelings and its categories are Receiving, Responding, Valuing, Organization, and Characterization (Ferraz \& Belhot, 2010). The Pscychomotor Domain includes the abilities and movements related to non-verbal communciation and its categories are Imitation, Manipulation, Articulation, and Naturalization (Ferraz \& Belhot, 2010).

It is hoped that by means of this study it is possible to analyze how the Open Safari case contributes, according to the students' perception, to the development of skills and competencies belonging to the Cognitive and Affective learning domains of the Bloom Taxonomy. Indications will thus be obtained of how this case appropriately responds to the demands of the Framework-Based Approach to Teaching in terms of providing the means for the construction of knowledge in the solution to problems.

The questionnaire adopted in this study was an adaptation of the one proposed and applied in both studies by Weil et al. $(1999,2001)$ to identify students' perception regarding the development of the skills and competencies suggested by the AECC and adapted with the benefits of using cases in studies, such as those by Campbell and Lewis (1999), Hassall, Lewis, and Broadbent (1998), Kimmel (1995), Knechel (1992), and Wines, Carnegie, Boyce, and Gibson (1994). The adaptations carried out were essentially: (i) a change of the Likert Scale of analysis (qualitative variables - non-metric) to a scale of 1 to 10 (quantitative variables - metrics). This alteration enables, for example, the mean to be calculated and the tests of mean to be carried out, which are essential 
for a more robust analysis of the data of this research; and (ii) in the respondent characterization section, indications were included regarding whether the students work and whether it is the first time they are taking the discipline. The groups of skills and competencies highlighted in the questionnaire were compared for the purposes of this research with the domains from the Bloom Taxonomy learning process (Table 2).

Table 2 Correlation between the scales of the data collection instrument and the learning objective levels of the Bloom Taxonomy

Categories of the Bloom Taxonomy Scales and subscales of abilities by Weil et al. $(1999,2001)$

1. Cognitive Domain

1.1 Knowledge

1.2. Understanding

1.3. Application

1.4. Analysis

1.5. Synthesis

1.6. Evaluation
Data Exploration (EXP)

Identifying the relevant data in the case

Organizing the data

Ability to identify the problem

Communication Skills (COM)

Listening skills

Written communication skills

Persuasion skills

Consolidation and Integration (CONS)

Integrated understanding of the different course components

Synthesis of the essential elements of the problem

Consolidation of the previous knowledge of the discipline

Summarization of the available information

Integration of the technical knowledge of the discipline

Judgment (JUD)

Improving judgment skills

Distinguishing between facts and opinions

Developing problem-solving skills

Elaboration of Problems (PROB)

Interpreting data

Thinking critically

Analytical skills

Thinking conceptually

Evaluating ideas

Visualization (VIS)

Considering different perspectives

Imagining the decision-making environment

Imagining the business operations

Relating theory with real-world practice

Applying the knowledge to new situations

Dealing with Uncertainties (UNC)

Making decisions with incomplete information

Dealing with uncertainty and ambiguity

Considering various solutions to business problems

Active Participation (ACT)

Actively participating in the learning process

Asking relevant questions

Increasing the motivation to study

Responsibility for one's own learning

Source: Elaborated by the authors. 
This comparison was carried out with the intention of verifying whether by resorting to this data collection instrument it would be possible to collect perceptions regarding the usefulness of the case at all levels of knowledge, especially the Cognitive level of the Bloom Taxonomy. For each one of the questions the students had to give a score from 1 to 10 according to their level of agreement in relation to the development of skills and competencies.

As the questionnaire from Weil et al. (1999) was adopted in full as the instrument for calculating the students' perception regarding the development of the skills and competencies reported in the second column of Table 2, it is observed that few of them are related to the Affective Domain and so the greatest emphasis of the discussions has concentrated on the Cognitive Domain. Nonetheless, this emphasis does not reduce the importance of that domain within the scope of this study and the questionnaire used to gather the data is wholly valid for calculating the students' perception with regards to improving skills of the affective order.

\section{RESEARCH PROCEDURES}

In order to achieve the research objective, data was gathered through questionnaires and focus groups. At the higher education institution (HEI) analyzed, the AT discipline is obligatory and taught in the sixth semester of the course, when the students have already taken the core disciplines (Introductory Accounting I, Introductory Accounting II, Intermediate Accounting I, Intermediate Accounting II, and Advanced Accounting), as well as ethics, statistics, and financial mathematics. Thus, when the Open Safari case is applied, it was considered not to be the students' first contact with the topics addressed in it. According to the course specifications, in the Accounting Theory discipline the students are expected to be able to establish associations between the theory and practice in a critical way and exercise the use of judgments and estimates.

The Open Safari case was applied for three semesters to five classes, two during the day and three in the evening (Table 3). One hundred fifty-nine students took part in the study by answering the questionnaire, with only 157 mentioning gender and whether they work or not and 151 mentioning whether it is the first time they are taking the discipline (Table 3). Most (139 students) were enrolled in the sixth period of the course (they were taking the discipline for the first time). The average age of the students was 22 .

In all of the classes, groups were formed of approximately eight elements each to develop the stages of the case. During each class session, the stages of the case were implemented by the students and handed in to the professor, in written form. Over the course of the semester, the contents of the discipline were addressed, inserting classes for discussions and clarifying doubts with the professors. At the end of the semester, some classes were reserved for the final presentation of the case, when the discussion and closure of the case also occurred in the form of a plenary between professors and students.

Table 3 Characterization of the respondents of the questionnaire

\begin{tabular}{|c|c|c|c|c|c|c|c|c|c|c|c|}
\hline \multirow{2}{*}{\multicolumn{2}{|c|}{ Characteristics }} & \multirow{2}{*}{\multicolumn{3}{|c|}{$\begin{array}{c}\text { 2nd semester of } 2013 \\
\text { Session }\end{array}$}} & \multirow{2}{*}{\multicolumn{3}{|c|}{$\begin{array}{c}\text { 1st semester of } 2014 \\
\text { Session }\end{array}$}} & \multirow{3}{*}{$\begin{array}{c}\text { 2nd semester of } 2014 \\
\text { Session } \\
\mathrm{N}\end{array}$} & \multirow{2}{*}{\multicolumn{3}{|c|}{$\begin{array}{l}\text { Total } \\
\text { Session }\end{array}$}} \\
\hline & & & & & & & & & & & \\
\hline & & D & $\mathbf{N}$ & Total & D & $\mathbf{N}$ & Total & & D & $\mathbf{N}$ & Total \\
\hline \multirow{3}{*}{ Gender } & $\mathrm{F}$ & 24 & 17 & 41 & 19 & 19 & 38 & 22 & 43 & 58 & 101 \\
\hline & $M$ & 10 & 8 & 18 & 5 & 20 & 25 & 13 & 15 & 41 & 56 \\
\hline & Total & 34 & 25 & 59 & 24 & 39 & 63 & 35 & 58 & 99 & 157 \\
\hline \multirow{3}{*}{ Work } & Yes & 23 & 24 & 47 & 14 & 33 & 47 & 31 & 37 & 88 & 125 \\
\hline & No & 11 & 1 & 12 & 10 & 6 & 16 & 4 & 21 & 11 & 32 \\
\hline & Total & 34 & 25 & 59 & 24 & 39 & 63 & 35 & 58 & 99 & 157 \\
\hline \multirow{3}{*}{$\begin{array}{l}\text { 1st time } \\
\text { they take } \\
\text { the AT } \\
\text { discipline }\end{array}$} & Yes & 32 & 23 & 55 & 24 & 30 & 54 & 30 & 56 & 83 & 139 \\
\hline & No & - & - & - & - & 8 & 8 & 4 & - & 12 & 12 \\
\hline & Total & 32 & 23 & 55 & 24 & 38 & 62 & 34 & 56 & 95 & 151 \\
\hline
\end{tabular}

$D=$ day $F=$ female $M=$ male $N=$ night $; A T=$ Accounting Theory.

Source: Elaborated by the authors. 
After concluding the case activities, but before publishing the final scores, a questionnaire was given (Weil et al., 2001) to the students in order to gather their perception regarding the use of the case as a teaching strategy in the AT discipline, as well as the achievement of the objectives of the Framework-Based Approach to Teaching and the accomplishment of the learning objectives inscribed in the Bloom Taxonomy.

In order to triangulate the analysis of this study and collect evidence regarding the use of the Open Safari case in the teaching-learning process, especially to give depth to the analyses regarding the development of skills and competencies using the tool in the AT discipline, five focus groups were carried out, two in the first semester (2013/2), of application of the case, two in the second (2014/1), and one in the third semester (2014/2). Each one of the focus groups was composed of students from the full-time and evening sessions who decided to take part voluntarily in the study. Precautionary ethical measures were taken with regards to protecting the image of the volunteers by providing clarifications concerning the research and its purpose, and the students expressed their agreement by signing a consent form (also obtained for the respondents of the questionnaire).

The focus groups were conducted by a moderator who carried out the role of encouraging the discussion of the questions and the presentation of personal opinions and could interfere when necessary with the aim of including topics for debate in order to promote or further some other one raised by the participants during the discussions. The main topics driving the debates were: (i) development of the skills and competencies; (ii) motivation; (iii) individual study and research or in group; (iv) practical corporate overview; (v) teamwork; (vi) difficulties and limitations; and (vii) performance in the discipline.

If the discussion did not develop from the first question, the moderator had at least two alternative questions that could be asked until achieving the objective or exhausting the debate. All of the focus groups were recorded, in audio and on video, and transcribed, enabling the analysis of their content and comparison with the answers to the questionnaires.

Forty students took part voluntarily in the focus groups, which were not uniform in terms of numbers (Table 4 ). The percentage of female participants was $68 \%$ and that of males was $32 \%$. The average age among the focus group participants was the same as the respondents of the questionnaire (22 years-old, without statistically significant differences). Also, $51 \%$ of the participants were full-time and $49 \%$ were from the evening session.

In order to protect the participants' image, their names were substituted by identification initials composed of two letters. Thus, over the course of the discussion of the results, when the participants' statements were presented, codes composed of the initial identifying the student were used together with the focus group and the respective semester (FG1; FG2; FG3, FG4, and FG5). For example, when there is a need to refer to the first student of the list (Table 4), who participated in the first focus group carried out in semester 2013/2, the code FRFG1 will be used. The qualitative data were analyzed by means of content analysis.

Table 4 Composition of the focus groups (FG)

\begin{tabular}{cccccccccc}
\hline & FG1 & & FG2 & & FG3 & & FG4 & FG5 \\
\hline ID & Session & ID & Session & ID & Session & ID & Session & ID & Session \\
\hline FR & Full time & AD & Evening & AG & Evening & MI & Full time & TA & Full time \\
\hline IS & Evening & AK & Evening & GS & Full time & VN & Full time & CH & Evening \\
\hline MR & Evening & YR & Full time & MN & Evening & CR & Full time & IF & Full time \\
\hline AD & Evening & FL & Evening & LU & Full time & WL & Evening & MA & Full time \\
\hline ME & Evening & VR & Evening & MS & Evening & RD & Evening & TO & Evening \\
\hline TS & Full time & BR & Evening & SR & Full time & & & DH & Full time \\
\hline AL & Full time & AL & Full time & TG & Evening & & & & \\
\hline GL & Full time & NT & Full time & VC & Evening & & & & \\
\hline LR & Full time & CL & Full time & VT & Evening & & & & \\
\hline JS & Full time & LC & Full time & & & & & & Total \\
\hline Total & 10 & Total & 10 & Total & 9 & Total & 5 & 6 \\
\hline
\end{tabular}

$I D=$ identifying initial, composed of two letters, which corresponds to the participating student.

Source: Elaborated by the authors. 
The statistical treatment of the data was operationalized using the Statistical Package for the Social Sciences (SPSS) program. In order to verify the statistical significance of the average perceptions of the students regarding the 31 skills and competencies, as well as the average perceptions of the students grouped into the Bloom Taxonomies, the non-parametric Wilcoxon test was applied. This test was used due to the study variables being ordinal and the non-normality of these variables identified using the KolmogorovSmirnov test. The confidence interval was $95 \%$ and the level of significance, used for all the tests, was $5 \%$. Thus, for the Wilcoxon test, if the results presented a $\mathrm{p}$-value $>0.05$, it will be considered that there are no significant differences. But if p-value $<0.05$, it will be considered that there are significant differences between the averages perceptions of the students.

\section{RESULTS}

The students' perception regarding the usefulness of the Open Safari case for the development of the 31 skills

and competencies listed in the questionnaire of the study is summarized in Table 5.

Table 5 Ranking of skills and competencies

\begin{tabular}{|c|c|c|c|c|c|c|c|c|c|}
\hline \multirow[t]{2}{*}{ Rank } & & \multirow{2}{*}{ Skills and competencies } & \multirow{2}{*}{$\mathbf{n}$} & \multirow[t]{2}{*}{$\overline{\mathrm{X}}$} & \multirow{2}{*}{ Mo } & \multirow[t]{2}{*}{ SD } & \multirow{2}{*}{ EU $(\%)$} & \multicolumn{2}{|c|}{$\begin{array}{l}\text { Weil et al. } \\
(2001)\end{array}$} \\
\hline & & & & & & & & Rank & M \\
\hline 1 & INC & Considering various solutions & 159 & 8.4 & 10 & 1.9 & 57 & 2 & 6.18 \\
\hline 2 & VIS & Practical overview of the decision-making process & 159 & 8.0 & 10 & 2.1 & 44 & 1 & 6.18 \\
\hline 3 & CONS & Integration of different subjects of the discipline & 159 & 7.7 & 8 & 1.9 & 63 & 6 & 5.50 \\
\hline 4 & PROB & Interpretation & 159 & 7.7 & 8 & 2 & 54 & 15 & 5.02 \\
\hline 5 & VIS & Relating theory and practice & 159 & 7.7 & 8 & 2.1 & 51 & 3 & 5.78 \\
\hline 6 & JUD & Judgment & 159 & 7.5 & 8 & 1.9 & 62 & 19 & 5.00 \\
\hline 7 & ACT & Responsibility for one's own learning & 159 & 7.5 & 7 & 1.9 & 50 & 14 & 5.12 \\
\hline 8 & PROB & Critical thinking & 159 & 7.5 & 8 & 2 & 53 & 9 & 5.22 \\
\hline 9 & VIS & Application of the knowledge & 159 & 7.5 & 7 & 1.8 & 52 & 5 & 5.51 \\
\hline 10 & PROB & Thinking conceptually & 159 & 7.5 & 8 & 2.1 & 51 & 15 & 5.02 \\
\hline 11 & CONS & Technical knowledge & 159 & 7.5 & 8 & 1.9 & 54 & 20 & 4.98 \\
\hline 12 & PROB & Analysis & 159 & 7.5 & 8 & 1.9 & 42 & 10 & 5.16 \\
\hline 13 & EXP & Identification of relevant data & 159 & 7.4 & 8 & 1.9 & 43 & 11 & 5.14 \\
\hline 14 & CONS & Consolidation of previous knowledge & 159 & 7.4 & 8 & 2.1 & 49 & 11 & 5.14 \\
\hline 15 & PROB & Evaluating ideas & 159 & 7.3 & 8 & 1.8 & 32 & 15 & 5.02 \\
\hline 16 & VIS & Overview of the workings of a company & 159 & 7.3 & 8 & 2.1 & 52 & 8 & 5.31 \\
\hline 17 & JUD & Problem solving & 158 & 7.3 & 8 & 1.9 & 40 & 18 & 5.01 \\
\hline 18 & JUD & Distinguishing facts from opinions & 159 & 7.2 & 8 & 2 & 40 & 4 & 5.55 \\
\hline 19 & VIS & Considering different perspectives and users & 158 & 7.2 & 8 & 2.1 & 70 & 7 & 5.35 \\
\hline 20 & EXP & Organization of information & 159 & 7.1 & 7 & 2.1 & 45 & 27 & 4.78 \\
\hline 21 & INC & Dealing with uncertainty and ambiguity & 159 & 7.1 & 8 & 1.9 & 45 & 24 & 4.88 \\
\hline 22 & EXP & Identification of problems & 159 & 7.1 & 7 & 2 & 58 & 21 & 4.96 \\
\hline 23 & CONS & Summarizing information & 159 & 7.0 & 8 & 1.9 & 75 & 22 & 4.92 \\
\hline 24 & $\mathrm{COM}$ & Written information & 159 & 7.0 & 7 & 2.1 & 63 & 31 & 4.16 \\
\hline 25 & CONS & Synthesis & 159 & 7.0 & 7 & 1.9 & 47 & 22 & 4.92 \\
\hline 26 & INC & Decision making with incomplete information & 159 & 7.0 & 7 & 1.9 & 49 & 11 & 5.14 \\
\hline 27 & $\mathrm{COM}$ & Listening skills & 159 & 6.9 & 8 & 2.3 & 56 & 28 & 4.73 \\
\hline 28 & ACT & Relevant questions & 159 & 6.9 & 8 & 2.1 & 42 & 24 & 4.88 \\
\hline 29 & ACT & Active participation & 158 & 6.8 & 7 & 2.3 & 51 & 26 & 4.86 \\
\hline 30 & $\mathrm{COM}$ & Persuasion & 159 & 6.8 & 8 & 2 & 45 & 29 & 4.57 \\
\hline 31 & ACT & Motivation & 159 & 6.1 & 7 & 2.6 & 45 & 30 & 4.49 \\
\hline
\end{tabular}

$S D=$ standard deviation; $E U=$ extremely useful (proportion of respondents that attributed a score 8, 9, or 10 on the scale for each question, considering the $E U$ case for the development of the skill and competency); Mo = mode; $n=$ number of respondents.

Source: Elaborated by the authors. 
The mean between 6.1 and 8.4 (above 5 for all the questions) suggests that the students positively perceived the usefullness of the case for developing the skills and competencies, thus corroborating with the AECC objectives (1990) that using cases serves the students in developing their communicative, intellectual, interpersonal, and attitudinal aptitudes, as well as general, business, and accounting knowledge, all of which are contained and ranked in Table 5. It bears mentioning that Weil et al. (2001) calculated a mean between 4.16 and 6.18 for the 31 skills described in Table 5, suggesting that the African students negatively perceived the development of some skills and competencies, such as using cases for teaching (for example, motivation, persuasion, listening skills, active participation, synthesis, and written communciation). The difference between the means of the African students' perceptions and those of the students in this study may be an indication of the effectiveness of the Open Safari case in developing skills and competencies needed to understand and apply IFRS.

It bears mentioning that the objectives of the FBAT and of the Open Safari of developing skills to think conceptually, make judgments, take decisions, and think critically (Hodgdon et al., 2011; IASB 2014; Jackling, 2013; Wells, 2011), feature among the 10 highest ranked skills and competencies by the students (positions 1, 6, 8, and 10). These results indicate the effectiveness of the Open Safari case in achieving the FBAT objectives.

The first question in the ranking is related with the students' exposure to the accounting choice process, considering various solutions for the same problem. In the students' reports, the possible existence of more than one answer in some situations was one of the greatest differences experienced, as reported by LUFG3: "It was really difficult for me because I still like a correct, defined answer. And the case went against what I liked" and MNFG3: "You discover new things, you open your mind to subjects you're not used to, but what's new always makes you uncertain. You aren't sure whether you're going in the right direction". In contrast, student JSFG1 stressed that

it's not always going to be very clear when you're in the company. You're going to have to use some judgment, even if subjective. So that really obliges us to think critically. I think that is the most interesting point in Open Safari.

In addition, at various points in the debates it was common for the participants to makes statements such as "I was reading by stage and I suddenly thought 'it's always the same question!'” (VTGF2) or "And it's not the same answer!" (GSFG3). It is perceived that the fact that the solutions to the questions of the Open Safari case are not standardized enables the discussion of various alternatives solutions to the same question. According to Bonnier et al. (2013), this is a way of developing the students' ability to make judgments, as the FBAT prescribes.

The second position in the ranking is occupied by the Visualization skill, which refers the students to the company environment, enabling them to establish associations with real situations and with these they are able to apply their knowledge. It is observed that this skill lies in the second highest degree of learning of Bloom's Cognitive Domain, called Synthesis (Table 2).

Besides expressions of an improvement in this skill in the questionnaire, it was possible to collect other expressions such as "Open Safari provided more reality. It is a practical case. Even though we aren't there, it provides details from Open that makes us sit down there within it and take decisions" (MEFG1) to reveal the perceived proximity with the case environment and with the associations that can be established with other practical contexts, such as "in the practice itself we will not experience a case like this... It covers more than what we will experience when we join the labor market" (ALFG1). It was possible to calculate that some students in fact perceived themselves to be within a decision-making environment, such as: "We work as if we were really in the company, having to come up with a solution. And if the boss comes and says that your work is wrong, even if it is you have to defend it" (TGFG3). This passage also indicates the development of the communication skill as well as the argumentation part. The aptitudes in the communication area occupied positions 24,27 , and 30 , based on the answers to the questionnaires; however, despite the classificatory order, the average score attributed to the development of this class of skill reached an average close to 7 . This skill is included in Bloom's first cognitive level - Knowledge.

Although in the answers to the questionnaires no great importance was attributed to the development of the communication skill, in the focus group this was sometimes mentioned in relation to the fact that not only did a decision need to be taken, but "knowing how to argue why you are taking take decision" (MRFG1). In addition, "exchanging opinions helped me to define, recognize, form my opinion, my view" (FRFG1); "we had to know in depth what we had done in order to be able to speak" (MEFG1); "I think that in the reading and interpretation part of the CPC it helps quite a lot, because you start to have another vision, even of the way that you lay out the data" (VNFG4); and "the discussion, the group work is good for that reason, it makes us think in both ways, not just my way" (MAFG5).

In third place in degree of importance, the ability to 
integrate the learning of contents of the discipline was observed, the respective Cognitive Domain category for this being Understanding. In addition, it is possible to perceive the importance of the aptitude in consolidating components by means of statements such as: "we observed the evolution of our knowledge and of our analysis skills" (VTFG3) and also "Yes, it (the case) is well linked to Accounting Theory, but it could also be used in International Accounting, as it concerns IFRS and the international standards and also involves other currencies and other places in the world' (RDFG4). It is also perceived that the case could be applied in other disciplines or periods of the course, depending on the curricular structure of each course.

The Judgment ability, one of the most sought by IFRS Education when elaborating the case, appears in sixth place in the ranking. This competency is developed in the third phase of the learning process of the Cognitive Domain (Application) and relates to the ability to distinguish between facts and opinions and with mastering problem solving. Based on Table 6, it bears mentioning that $62 \%$ of the respondents considered the case to be extremely useful for developing this skill. Likewise and taking into account the classes of statistically equal results shown in Table 6, the Judgment skills feature in positions 5, 6, and 7 , always with an average greater than 7 and mode equal to 8 in all the related questions; that is, they are evaluated by the students as extremely useful.

Some students mentioned that exercising judgment was one of the most difficult tasks in the execution of the case, and TSFG1 stressed:

We are used to wanting a more exact answer, and it is something that comes from the international standards, the question of judging and you have to decide what you are going to do, you have to, based on something theoretical.

In addition, the indication from MEFG1 stands out in stating that "accounting has a lot of that, what is for one isn't for another, so it's down to your judgment... in the Open Safari case you have to judge at all times".

Great importance was also attributed to developing the ability to interpret data (fourth place in the ranking in Table 5), which is also connected to the aptitude of analyzing and thinking conceptually and critically evaluating ideas. This concerns the fourth category of Bloom 's Cognitive Domain, called Analysis (Table 2). For one student, the case contributed to the FBAT, since

Not only with the adaptation of IFRS, but we had an initial idea and the Open Safari case proposes a methodology and a totally new, totally updated concept. It presents practical examples, but it always wants to highlight the conceptualization. (WLFG4)
Another participant also stressed with regards to the ability to think conceptually and critically that:

I was studying definitions of business combinations. Oh, you have to acquire a company. So, what is a company? There has to be inputs, outputs, and processes. What are inputs? The result of outputs. What is a process? The result of inputs and outputs... (SRFG3)

leading to the understanding that there is a driving force towards the process of conceptual rationalization. In addition, expressions such as:

It was sad for me to discover that assets were not a set of goods and rights, I was disappointed and shocked. Up until then, from the first period, I had that concept... So, it was much easier for me after I understood the concept. (TAFG5)

indicate the need to learn to think conceptually starting from the first disciplines of the course. These results are consistent with the one laid out by Wells (2011) regarding the ability of the FBAT to entrench the teaching in the concepts underlying the accounting standards, enabling the students to understand the standards via an understanding of the concepts that gave rise to them. And they are also connected with the thinking of Street (2002) with regards to the need to teach the students to think.

The students also reported that they improved their ability to relate with each other in groups, "it was an opportunity for us to converse with other people... and with regards to teamwork, one particular ability that was developed was patience" (MRFG1), "we criticized and that person that was being criticized did not feel offended" ((TGFG3) and also coming together through dialogue "the tasks do that, we get to know the person better; sometimes, you don't even like the person, but when you're going to do the work you discover who the real person is, you even become friends" (TAFG5). There were also reports of a break with behavioral patterns:

That is something that I didn't expect to say. It's a source of pride. So, in this task, I had to say: I don't know. Help me. In a way, it helps with rapport, because, for example, where I work, there are many times I don't know and pride prevents me from asking. In this case, I developed that part. (MEFG1)

The writing skill was also reported in some fragments such as "I often had to defend myself in writing, and when you were speaking... you had to give the impression you were right" (GSFG3).

Other reports also enabled reflections regarding the teaching methodologies and teacher's positioning, such as in "we had the freedom to discuss, converse, so that way the teacher's view also changed" (MEFG1). The statement 
from CHFG5 also explains a deficiency of teaching based on the teacher-centered, transmissive model:

\begin{abstract}
Although the professor is there teaching in the lecture, although you are learning something, you forget. But when the theory is linked to the practice, what the professor teaches is in the practice, and I would learn much more.
\end{abstract}

Moreover, with relation to evaluation mechanisms "the greatest motivational factor was the way it was evaluated. I have great difficulty in written evaluations, exams, but with presentations, with speaking I am more at ease" (IFFG5).

It is also observed that attitudinal skills (ACT), except "responsibility for one's own learning" - seventh place -, represented the bottom positions in the ranking in relation to the other skills and competencies, which does not represent a negative result in itself, since the averages and mode were higher than 6.

The participants' narratives also indicated the consolidation with previous knowledge - a skill that occupied $14^{\text {th }}$ place in the ranking - derived from the other disciplines of the course, as can be seen through the following passage:

It is precisely due to the fact that Open Safari covers various disciplines and different information that were absent in the previous periods. We worked on things one by one. If fixed assets were mixed with intangibles in a single exercise it caused discomfort. In Open Safari we are obliged to have that broad overview. (AGFG3).

Others also emphasized that the case "encourages the student to know more, to search for that research. The research is forced on the student, it isn't a decision to want to search" (WLFG4), reinforced by the opinion of AGFG3: "I think that Open Safari despite its complexity, and precisely because of it, makes us more dedicated. Searching and trying to solve, I think that is good. It's tiring, but it's worth it." (AGFG3).

Occupying the last position in the ranking elaborated based on the questionnaires, motivation was also a highlight in the group debate and thinking of the case as an initiative of the IASB instigated one student to state "We asked ourselves: do a case that is globally known in the degree?! Do we have the ability to do that? So, when we got it right, boy!" (MNFG3). The motivation also came from the incentive of other classmates: "my answer was not totally sufficient. But, with a bit from so-and-so and another bit from someone else, it became the complete answer... So that provides motivation!" (TGFG3). In addition, statements such as "Open Safari made us open our minds" (MSFG3) and "independently of the score you wanted to learn" (FRFG1) were considered expressions associated with motivation.

Motivation occupied the next-to-last position (average of 4.49) in the ranking of the study by Weil et al. (2001). One of the explanations for motivation occupying the last position in the ranking of this study (despite the positive average of 6.1) may be the fact that the students had contact with the FBAT philosophy, for the first time, in the sixth semester of the course in the AT discipline. The teaching on the Accounting Sciences course at the university, which is the object of this study, is based on the traditional methodology, characterized by the transmission of information, fragmented disciplines, evaluations that require memorizing, and on the professor as the spreader of knowledge. In this context, when the Open Safari case was applied, the students were exposed to a methodology that required research, causing insecurity and demotivation.

In light of this, the need is stressed for an accountant's training to be carried out in the three stages prescribed by Wells and Tarca (2014a): Awareness (introductory disciplines), Understanding (intermediate disciplines), and Competency (advanced disciplines). That is, the FBAT philosophy should be applied from the start of the Accounting Sciences course, as suggested by TAFG5:

\begin{abstract}
In conceptual terms, I'll speak for myself, at the beginning of the active period it was a set of goods and rights and then I understood that it was a past event that generates future benefits and is controlled. So, it was much easier for me after I understood the concept.
\end{abstract}

The report from TAFG5 reflects the argument concerning the effect of the first contact with the case: "in the beginning we get a shock because in our heads there is that conservatism, which is technical. The debit and the credit. And Open Safari makes you think, for example, is it an asset?"

In order to verify whether the averages are statistically different, the non-parametric Wilcoxon test was applied, since the data did not present a normal distribution and the variables are ordinal. In Table 6 the results for this test are recorded. The formation of 10 groups is perceived with statistically different averages $(\mathrm{p}<0.05)$. 
Table 6 Analysis of the ranking of the skills and competencies by significance

\begin{tabular}{|c|c|c|c|c|c|c|c|c|}
\hline Rank* & Groups & $\begin{array}{c}\text { Bloom } \\
\text { Taxonomy }\end{array}$ & & Skills and competencies & $\bar{x}$ & W & $\mathrm{p}>0.05^{* *}$ & $\mathbf{p}<0.05^{* * *}$ \\
\hline 1 & 1 & EVAL & INC & Considering various solutions & 8.38 & & & \\
\hline 2 & 2 & SYNT & VIS & Practical overview of the decision-making process & 7.99 & -2.49 & & 0.013 \\
\hline 3 & 3 & COMP & CONS & Integration of different subjects of the discipline & 7.72 & -2.02 & & 0.043 \\
\hline 4 & \multirow{2}{*}{4} & ANAL & PROB & Interpretation & & -0.01 & 0.995 & \\
\hline 5 & & SYNT & VIS & Relating theory and practice & 7.70 & -0.37 & 0.710 & \\
\hline 6 & \multirow{4}{*}{5} & APPL & JUD & Judgment & 7.70 & -2.07 & & 0.039 \\
\hline 7 & & AFF & ATT & Responsibility for one's own learning & 7.52 & -0.13 & 0.898 & \\
\hline 8 & & ANAL & PROB & Critical thinking & 7.51 & -0.68 & 0.494 & \\
\hline 9 & & SYNT & VIS & Application of knowledge & 7.50 & -0.79 & 0.427 & \\
\hline 10 & \multirow{8}{*}{6} & ANAL & PROB & Thinking conceptually & 7.49 & -1.98 & & 0.048 \\
\hline 11 & & COMP & CONS & Technical knowledge & 7.47 & -0.24 & 0.808 & \\
\hline 12 & & ANAL & PROB & Analysis & 7.46 & -0.27 & 0.790 & \\
\hline 13 & & KNOW & EXP & Identification of relevant data & 7.45 & -0.73 & 0.466 & \\
\hline 14 & & COMP & CONS & Consolidation of previous knowledge & 7.43 & -0.76 & 0.448 & \\
\hline 15 & & ANAL & PROB & Evaluating ideas & 7.38 & -1.47 & 0.141 & \\
\hline 16 & & SYNT & VIS & Overview of the workings of a company & 7.28 & -1.43 & 0.153 & \\
\hline 17 & & APPL & JUD & Problem solving & 7.28 & -1.59 & 0.112 & \\
\hline 18 & \multirow{5}{*}{7} & APPL & JUD & Distinguishing facts from opinions & 7.25 & -2.12 & & 0.034 \\
\hline 19 & & SYNT & VIS & Considering different perspectives and users & 7.24 & -0.72 & 0.943 & \\
\hline 20 & & KNOW & EXP & Organizing information & 7.19 & -0.85 & 0.396 & \\
\hline 21 & & EVAL & INC & Dealing with uncertainty and ambiguity & 7.09 & -1.31 & 0.191 & \\
\hline 22 & & KNOW & EXP & Identifying problems & 7.09 & -0.94 & 0.345 & \\
\hline 23 & \multirow{7}{*}{8} & COMP & CONS & Summarizing information & 7.07 & -2.01 & & 0.044 \\
\hline 24 & & KNOW & COM & Written communication & 7.03 & -0.41 & 0.684 & \\
\hline 25 & & COMP & CONS & Synthesis & 7.03 & -0.15 & 0.879 & \\
\hline 26 & & EVAL & INC & Taking decisions with incomplete information & 7.02 & -0.57 & 0.571 & \\
\hline 27 & & KNOW & COM & Listening skills & 7.00 & -0.38 & 0.705 & \\
\hline 28 & & AFF & ATT & Relevant questions & 6.91 & -1.03 & 0.300 & \\
\hline 29 & & AFF & ATT & Active participation & 6.89 & -1.61 & 0.107 & \\
\hline 30 & 9 & KNOW & COM & Persuasion & 6.82 & -2.46 & & 0.014 \\
\hline 31 & 10 & AFF & ATT & Motivation & 6.75 & -3.58 & & 0.000 \\
\hline
\end{tabular}

W = non-parametric Wilcoxon test.

* Rank grouped by statistically identical means; ${ }^{* *} p$-value for the Wilcoxon test; ${ }^{* * *} p$-value for the Wilcoxon test by statistically identical group.

Source: Elaborated by the authors.

The data were paired in the following way: the mean of 8.38 from the "considering various solutions" question was paired with the mean of 7.99 from the "practical overview of the decision-making process" question to verify whether these means are equal. The result of the Wilcoxon test $(z=-2.49$; sig $=0.013)$ suggests that the means are different. Thus, the three highest ranked questions presented a statistically different mean $(\mathrm{p}=$ 0.013 and 0.043 , respectively), as shown in Table 6 . The first question is related with the student's exposure to the accounting choice process, considering various solutions for the same problem. The second uses the case to enable the student to visualize the reality and the difficulties faced by company decision-makers, associating theory and practice. The third refers to the students' perception that the case can help in integrating the various contents addressed in the AT discipline.
Of the 10 highest ranked questions analyzed in light of the Bloom Taxonomy, three form part of the synthesis group (SYTH) and another three form part of the Analysis group (ANAL). These skills and competencies are related with the third stage of the FBAT. Moreover, the strategy of using the Open Safari case aims for a progressive evolution of the students with regards to establishing IFRS estimates and other judgments that begin with awareness, move on to understanding, and reach the highest level, which is that of competency (third stage).

Bloom's Knowledge group (KNOW) is the only group that does not feature among the 10 highest ranked questions (Table 6). However, the mean of question 24 , which occupies the $10^{\text {th }}$ position, does not differ statistically from the next seven questions (up to the $17^{\text {th }}$ position). Thus, it is possible to conclude that in the students' perception the Open Safari case helps in 
the development of skills and competencies of all of the Bloom Taxonomy groups, as can be seen in Table 7, by achieving their main objective of improving the students' ability to carry out judgments and estimates $\left(6^{\text {th }}\right.$ place in the ranking) needed to apply IFRS $\left(9^{\text {th }}\right.$ place in the ranking) in the accounting treatment of economic transactions and events, as well as helping the students to think conceptually $\left(10^{\text {th }}\right.$ place in the ranking).

The joint analysis of the ranking of the skills and competencies developed enables it to be inferred that the first place is occupied by the ability to Deal with Uncertainties, which includes the presence of incomplete information, ambiguity, and the possible existence of more than one solution to a problem in a given context. This ability is contained in the highest level of learning of the Cognitive Domain, that is, at the Evaluation level, and in this stage it can be considered that the effective consolidation of knowledge or the legitimacy of learning a particular content has been achieved. This means that the Open Safari case fulfills its educational objectives, and besides accessing the most sophisticated levels of the Cognitive Domain, it does more intensely.

Table 7 Skills and Competencies from Weil (2001) and Bloom Taxonomy

\begin{tabular}{|c|c|c|c|c|c|c|c|}
\hline \multicolumn{2}{|r|}{ Weil (2001) } & \multicolumn{6}{|c|}{ Bloom Taxonomy } \\
\hline \multirow{2}{*}{\multicolumn{2}{|c|}{ Ranking skills and competencies }} & \multicolumn{6}{|c|}{ Cognitive Domain } \\
\hline & & 1. Knowledge & 2. Understanding & 3. Application & 4. Analysis & 5. Synthesis & 6. Evaluation \\
\hline 1 & Uncertainty & & & & & & $x$ \\
\hline 2 & Visualization & & & & & & \\
\hline 3 & Consolidation & & $x$ & & & & \\
\hline 4 & Elaboration of Problems & & & & $X$ & & \\
\hline 5 & Visualization & & & & & $x$ & \\
\hline 6 & Judgment & & & $x$ & & & \\
\hline 8 & Elaboration of Problems & & & & $x$ & & \\
\hline 9 & Visualization & & & & & & \\
\hline 10 & Elaboration of Problems & & & & $\mathrm{X}$ & & \\
\hline
\end{tabular}

Source: Elaborated by the authors.

The means of the students' perceptions by categories of the Bloom Taxonomy and Weil et al. (2001) are presented in tables 8 and 9 , respectively. The means of the Synthesis, Evaluation, and Analysis categories are not statistically different (Table 8). Thus, the students consider the Open Safari case to be useful especially for the development of skills and competencies that involve these abilities. The Application and Knowledge categories show similar means to each other and are statistically different from the other categories. Knowledge and Affective Domain have the lowest means and these are statistically different from those of the other groups.

Table 8 Mean per group - Bloom Taxonomy

\begin{tabular}{|c|c|c|c|c|c|}
\hline Category & Initial & $\overline{\mathrm{x}}$ & W & $p>0.05$ & $\mathrm{p}<0.05$ \\
\hline Synthesis & SYNT & 7.53 & & & \\
\hline Evaluation & EVAL & 7.49 & -0.903 & 0.367 & \\
\hline Analysis & ANAL & 7.48 & -0.589 & 0.556 & \\
\hline Application & APPL & 7.34 & -2.502 & & 0.012 \\
\hline Understanding & UND & 7.32 & -0.250 & 0.803 & \\
\hline Knowledge & KNOW & 7.20 & -3.740 & & 0.000 \\
\hline Affective Domain & AFF & 6.84 & -2.850 & & 0.004 \\
\hline
\end{tabular}

W = non-parametric Wilcoxon test.

Source: Elaborated by the authors.

Weil et al. (2001) separate Bloom's Affective Domain category into two: Communication Skills and Active
Participation. These two categories did not present a statistically significant difference in the test of means. 
Table 9 Mean per group - Weil (2001)

\begin{tabular}{|c|c|c|c|c|c|}
\hline Category & Initial & $\overline{\mathrm{x}}$ & $\mathbf{W}$ & $p>0.05$ & $p<0.05$ \\
\hline Visualization & VIS & 7.53 & & & \\
\hline Dealing with Uncertainties & INC & 7.49 & -0.903 & 0.367 & \\
\hline Elaboration of Problems & PROB & 7.48 & -0.589 & 0.556 & \\
\hline Judgment & JUD & 7.34 & -2.502 & & 0.012 \\
\hline Consolidation and Integration & CONS & 7.32 & -0.250 & 0.803 & \\
\hline Exploring Data & EXP & 7.20 & -1.446 & 0.148 & \\
\hline Skills and Competencies & COM & 6.90 & -4.245 & & 0.000 \\
\hline Active Participation & $\mathrm{ACT}$ & 6.84 & -1.323 & 0.186 & \\
\hline
\end{tabular}

W = non-parametric Wilcoxon test.

Source: Elaborated by the authors.

The students were questioned regarding the three main benefits of the Open Safari case in the list of 31 skills and competencies. The results, reported in Table 10, are consistent with the mean of the students' perception for each benefit of the case, denoting that the students perceived the visualization of problems of the company environment, the ability to deal with uncertainties, and the analysis of data as the main benefits of the case.

Table 10 Three main skills and competencies developed with the case

\begin{tabular}{|c|c|c|c|c|c|c|c|c|c|c|c|c|}
\hline \multicolumn{2}{|c|}{$\begin{array}{l}\text { Weil } \\
(2001)\end{array}$} & \multicolumn{2}{|c|}{ Bloom Taxonomy } & \multicolumn{3}{|c|}{$1^{\text {st }}$ place } & \multicolumn{3}{|c|}{$2^{\text {nd }}$ place } & \multicolumn{3}{|c|}{$3^{\text {rd }}$ place } \\
\hline C & $\bar{x}$ & C & $M$ & $\mathbf{Q}$ & $\%$ & Rank & $\mathbf{Q}$ & $\%$ & Rank & $\mathbf{Q}$ & $\%$ & Rank \\
\hline VIS & 7.53 & SYNT & 7.53 & 28 & 25 & 2 & 39 & 32 & 1 & 29 & 23 & 1 \\
\hline INC & 7.49 & EVAL & 7.49 & 30 & 27 & 1 & 28 & 23 & 2 & 24 & 19 & 3 \\
\hline PROB & 7.48 & ANAL & 7.48 & 16 & 15 & 3 & 19 & 15 & 3 & 27 & 21 & 2 \\
\hline JUD & 7.34 & APPL & 7.34 & 11 & 10 & 4 & 9 & 7 & 5 & 11 & 9 & 5 \\
\hline CONS & 7.32 & COMP & 7.32 & 9 & 8 & 5 & 12 & 10 & 4 & 16 & 13 & 4 \\
\hline EXP & 7.20 & KNOW & 7.20 & 5 & 5 & 6 & 6 & 5 & 6 & 7 & 6 & 7 \\
\hline COM & 6.90 & KNOW & 7.20 & 2 & 2 & 7 & 2 & 2 & 7 & 2 & 2 & 8 \\
\hline \multirow[t]{2}{*}{ ACT } & 6.84 & EFFE & 6.84 & 9 & 8 & 5 & 8 & 7 & 5 & 10 & 8 & 6 \\
\hline & & & & 110 & 100 & & 123 & 100 & & 126 & 100 & \\
\hline
\end{tabular}

C = Category; $Q=$ Quantity of students.

Source: Elaborated by the authors.

The students attributed a score of 7.73 (mean) to the Open Safari case and most (mean of 7.59) recommend that the case is applied in the AT discipline. It bears mentioning that in the curricular structure of the HEI that is the object of this study, the AT discipline is taught in the sixth semester of the course, when the students have already concluded the introductory, intermediate, and advanced disciplines of accounting (that is, after finishing stage 3 proposed by the FBAT). Perhaps for institutions in which the AT discipline is taught in the second period of the course, for example, the application of the Open Safari case would not be suitable.

Nevertheless, the students believe that the case can be used in another discipline, provided there is the foundation derived from the introductory, intermediate, and advanced disciplines, which could take place in different semesters in the degree courses in accounting. According to MEFG5, "the case mixes Accounting Theory with International Accounting, and that helps quite a lot in the development of the work". This comment reflects the contribution of the case to the disciplines studied in the sixth semester at the HEI in question.

\section{FINAL REMARKS}

Convergence with IFRS has resulted in a need for professional development in exercising choices, judgments, and estimates, due to the degree of subjectivity contained in these standards. IFRS Education has thus made efforts to produce formative material that can meet this demand.
The Open Safari case is one of these and the case study mentioned was produced to serve as an FBAT instrument in teaching related to non-financial assets.

The data in this study were gathered via applied questionnaires and focus groups carried out with students 
of the AT discipline that used the case, in 2013 and 2014, at a Brazilian university. The results obtained were produced by means of qualitative (content analysis) and quantitative (non-parametric means tests) analyses.

Based on the results found and taking the students' opinion into account, the following conclusions stand out: (i) applying the case was shown to be effective in achieving the objectives proposed by the educational initiative of the IASB, for the FBAT, which are the development of the ability to exercise judgment, carry out estimates, and choose appropriate alternatives for each corporate context; (ii) by using the Open Safari case it was possible to cover the whole of stage 3 (competency) proposed by the FBAT, which is compliant with the learning levels of the Cognitive Domain of the Bloom Taxonomy; (iii) the most developed skills and competencies are those linked with visualizing the real decision-making environment and unfolding problems; (iv) the greatest occurrences of improved skills and competencies are located at the highest levels of the Cognitive Domain of the Bloom Taxonomy, which may show the case's refinement in achieving its learning objectives; (v) the Open Safari case was shown to be efficient in the FBAT and the students reported that it is highly applicable to disciplines related with IFRS and AT; and (vi) the results are compliant with those from Hilton and Johnstone (2013), Hodgdon et al. (2011), Jackling et al., 2013, and Weil et al. (1999, 2001), who indicate the effectiveness of active methodologies such as cases for teaching in the development of skills and competencies, especially in accounting courses.

The results of this study can be useful for the different participants in the IFRS teaching-learning process: teachers, students, standardizing bodies, and regulators. This is primarily due to the fact that the Open Safari case has been shown to be effective in the development of skills and competencies needed for the application of these standards. Thus, it is recommended that the use of cases for teaching should be incentivized in Accounting Sciences courses, above all Open Safari, in disciplines that address the international accounting standards and their application in AT. However, it is suggested that the use of IFRS Education material should be institutionalized, especially the Open Safari case for the FBAT, so that the initial resistance faced by the students and the questions regarding the lack of continuity in the application of the case are mitigated. The lack of institutionalization may be an explanatory factor for the low mean of the motivation item in the questionnaire, since students see the effort to solve the case as the isolated initiative of some teachers.

Future research could be dedicated to analyzing the effects of using the Open Safari case with female and male students, similarly to the study by Weil et al. (2001), as well as verifying whether the level of development of skills and competencies is different between students that study during the day or in the evening and between those that have already had some professional experience in a company.

\section{REFERENCES}

Accounting Education Change Commission. (1990). Objectives of education for accountants. Position number one. Issues in Accounting Education, (5), $307-$ 312.

Bonnier, C., Demerens, F., Hossfeld, C., \& LeMahn, A. (2013). A French experience of an IFRS transition. Issues in Accounting Education, 28(2), 221-234.

Braunbeck, G. O., \& Wells, M. J. C. (2015). Stage 3 Teaching notes that accompany the Build it yourself case study. London: IFRSF Publications Department.

Campbell, J. E., \& Lewis, W. F. (1991). Using cases in accounting classes. Issues in Accounting Education, 6(2), 276-283.

Coetzee, S. A., \& Schmulian, A. (2013). The effect of IFRS adoption on financial reporting pedagogy in South Africa. Issues in Accounting Education, 28(2), 243-251.

Dewey, J. (1981). The philosophy of John Dewey. (J. J. McDermott, Ed.) (2nd. ed.). Chicago, IL: The University of Chicago Press.

Ferraz, A. P. C. M., \& Belhot, R. V. (2010). Taxonomia de
Bloom: revisão teórica e apresentação das adequações do instrumento para a definição de objetivos instrucionais. Gestão e Produção, 17(2), 421-431.

Hassall, T., Lewis, S., \& Broadbent, M. (1998). Teaching and learning using case studies: a teaching note. Accounting Education: an International Journal, 7(4), 325-334.

Hilton, S. R., \& Johnstone, N. (2013). The IFRS transition and accounting education: a Canadian perspective post-transition. Issues in Accounting Education, 28(2), 253-261.

Hodgdon, C., Hughes, S. B., \& Street, D. L. (2011). Framework-based teaching of IFRS judgement. Accounting Education: an International Journal, 20(4), 415-439.

International Accounting Standard Board. (2013). Normas internacionais de relatório financeiro (IFRS). London: IFRSF Publications Department.

International Accounting Standard Board. (2014). A guide through IFRS. London: IFRSF Publications Department. 
International Accounting Standard Board. (2015). Financial reporting standards for the world economy. London: IFRSF Publications Department.

International Accounting Standards Committee. (2006). Annual report 2005. London: IASC Publications Department.

Jackling, B. (2013). Global adoption of International Financial Reporting Standards: implications for accounting education. Issues in Accounting Education, 28(2), 209-220.

Jackling, B., De Lange, P. A., \& Natoli, R. (2013). Transitioning to IFRS in Australian classrooms: impact on teaching approaches. Issues in Accounting Education, 28(2), 263-275.

Kabureck, G. (2016). The case for principles-based accounting. Retrieved from https://www. complianceweek.com/news/news-article/the-case-forprinciples-based-accounting\#.Wa8EiNGQzIV

Kimmel, P. A. (1995). Framework for incorporating critical thinking into accounting education. Journal of Accounting Education, 13(3), 299-318.

Knechel, W. R. (1992). Using the case method in accounting instruction. Issues in Accounting Education, $7(2), 205-217$.

LeBlanc, M., Léger, M. T., Lang, M., \& Lirette-Pitre, N. (2015). When a school rethinks the learning environment: a single case study of a new school designed around experiential learning. ProcediaSocial and Behavioral Sciences, 174, 3577-3586.

Marin, E. (2015). Experiential learning: empowering students to take control of their learning by engaging them in an interactive course simulation environment. Procedia - Social and Behavioral Sciences, 180, 854-859.

Nath, J. L. (2005). The roles of case studies in the educational field. International Journal of Case Method Research \& Application, XVII (3), 396-400.

Rothwell, W. J., \& Kazanas, H. C. (1992). Mastering the instructional design process: a systematic approach. San Francisco, CA: Jossey-Bass.

Schipper, K. (2003). Principles-based accounting standards (commentary). Accounting Horizons, 17(1), 61-72.

Street, D. L. (2002). An interview with Sir David Tweedie. Journal of International Financial Management and Accounting, 13(1), 73-100.

Weil, S., Laswad, F., Frampton, C., \& Radford, J. (1999). Cultural and other influences on student perceptions of the use of case studies and study groups in management accounting. Commerce Division Discussion Paper Series 62. New Zealand: Lincoln University.

Weil, S., Oyelere, P., Yeoh, J., \& Firer, C. (2001). A study of students' perceptions of the usefulness of case studies for the development of finance and accounting-related skills and knowledge. Accounting Education, 10(2), 123-146.

Wells, M. J. C. (2011). Framework-based approach to teaching principles-based accounting standards. Accounting Education: an International Journal, 20(4), 303-316.

Wells, M. J. C., \& Tarca, A. (2013). Notas do professor que acompanham o estudo de caso da Open Safari. London: IFRSF Publications Department.

Wells, M. J. C., \& Tarca, A. (2014a). Estágio 3 - Ativos nãofinanceiros: estudo de caso da Open Safari. London: IFRSF Publications Department.

Wells, M. J. C., \& Tarca, A. (2014b). Introdução à abordagem de Ensino Embasada na Estrutura Conceitual para imobilizado e outros ativos não financeiros. London: IFRSF Publications Department.

Wells, M. J. C., \& Tarca, A. (2014c). Estágio 1 - Imobilizado. London: IFRSF Publications Department.

Wines, G., Carnegie, G., Boyce, G., \& Gibson, R. (1994). Using case studies in the teaching of accounting. Deakin University, Victoria: Australian Society of Certified Practising Accountants. 